[3] Johnson CJ, Reilly KM, Murray KM. Etanercept in juvenile rheumatoid arthritis. Annals of Pharmacotherapy 2001;35:464-71.

Disclosure of Interests: None declared

DOI: 10.1136/annrheumdis-2019-eular.7316

\section{AB1372-HPR THE INVESTIGATION OF THE RELATIONSHIP BETWEEN PSYCHOSOCIAL STATUS OF CHILDREN WITH JIA AND PARENTS}

Aykut Özçadırcı ${ }^{1}$, Aybüke Seven ${ }^{1}$, Gamze Arın ${ }^{1}$, Yasemin Özel Aslıyüce ${ }^{1}$, Fatma Birgül Kumbaroğlu' ${ }^{1}$, Nur Banu Karaca', Selcan Demir ${ }^{2}$, Yelda Bilginer ${ }^{2}$, Edibe Ünal ${ }^{1}$, Seza Özen ${ }^{2} .{ }^{1}$ Hacettepe University Faculty of Physical Therapy and Rehabilitation, Ankara, Turkey, ${ }^{2}$ Hacettepe Universiy Faculty of Medicine, Department of Pediatric Rheumatology, Ankara, Turkey

Background: Juvenile idiopathic arthritis (JIA) is a heterogeneous group of diseases characterized by unknown origin arthritis that begins before the age of 16 years (1). Therefore, families are often affected by the disease of children. Parents and children often disagree with assessing different aspects of disease activity in JIA (2).

Objectives: The aim of this study is to investigate the relationship between children with JIA and their parents' psychosocial status.

Methods: A total of 345 children with JIA and their parents were included in the study $(n=690)$. Juvenile Arthritis Biopsychosocial Questionnaire (JAB-Q) was administered to the subjects (3). The psychosocial status of the individuals was evaluated by this questionnaires.

Results: The mean age of children included in the study $(n=345)$ was $12.32 \pm 3.76$ years. While the median value of the Child Psychosocial score was 10 (min: 0 max: 38 ), the median value of the Parent Psychosocial score was 6 (min: 0 max: 20). Correlation coefficients and statistical significance were calculated by using the Pearson test. A positive low correlation was found between the psychosocial status of the child and parents $(r=0.273, p<0.001)$ (Table 1).

Table 1. Correlations

\begin{tabular}{|c|c|c|c|c|}
\hline \multirow{6}{*}{$\begin{array}{l}\text { JAB- } \\
Q\end{array}$} & \multirow{3}{*}{$\begin{array}{c}\text { Child } \\
\text { Psychosocial }\end{array}$} & $r$ & 1,00 & 0,283 \\
\hline & & $p$ & & 0,000 \\
\hline & & $\mathrm{n}$ & 345 & 345 \\
\hline & \multirow{3}{*}{$\begin{array}{l}\text { Parents } \\
\text { Psychosocial }\end{array}$} & $r$ & 0,283 & 1,00 \\
\hline & & $\bar{p}$ & 0,000 & \\
\hline & & $\bar{n}$ & 345 & 345 \\
\hline
\end{tabular}

Conclusion: It was observed that there was a low relationship between the psychosocial status of children and parents. It was concluded that child and parents psychosocial status may be affected by other variables such as high disease activity, school attendance. Further studies are needed in this area including different variables and interaction psychosocial status.

\section{REFERENCES}

[1] Prakken, B., Albani, S., \& Martini, A. (2011). Juvenile idiopathic arthritis. The Lancet, 377(9783), 2138-2149.

[2] Garcia-Munitis P, Bandeira M, Pistorio A, Magni-Manzoni S, Ruperto N, Schivo A, et al. Level of agreement between children, parents, and physicians in rating pain intensity in juvenile idiopathic arthritis. Arthritis Rheum 2006;55:177-83.

Disclosure of Interests: None declared

DOI: 10.1136/annrheumdis-2019-eular.7319 AB1373-HPR

\section{AB1373-HPR BIOPSYCHOSOCIAL CHARACTERISTICS OF INPATIENTS, OUTPATIENTS AND PATIENTS WHO ATTEND A GROUP EXERCISE SESSIONS REGULARLY}

Yasemin Özel Aslıyüce, Aykut Özçadırc ${ }^{2}$, Gamze Arın ${ }^{3}$, Aybüke Seven ${ }^{3}$, Nur Banu Karaca ${ }^{4}$, Fatma Birgül Kumbaroğlu ${ }^{3}$, Edibe Ünal ${ }^{3}$, Şule Apraș Bilgen ${ }^{2}$. ${ }^{1}$ Institution of Health Sciences, Ankara, Turkey; ${ }^{2}$ Institution of Health Sciences, Ankara, Turkey; ${ }^{3}$ Institution of Health Science, Ankara, Turkey; ${ }^{4}$ Institution of Health Science, Ankara, Turkey

Background: Studies show that patients' biopsychosocial characteristics may be affected by various factors such as inpatient, outpatients, exercise intervention regularly. [1]. No studies have been found to examine this situation in the literature.
Objectives: The aim of this study was to investigate the biopsychosocial characteristics of patients with rheumatic diseases who were inpatients, outpatients and participated in an exercise intervention regularly.

Methods: A total of 105 patients were included in the study (inpatient, outpatient exercise intervention) (Table 1). For exercise intervention group, BETY as a biopsychosocial exercise model was applied 3 days a week for 3 months [2]. Biopsychosocial characteristics of the patients included in the study were evaluated by BETY- Biopsychosocial Questionnaire (BETY-BQ) [3]. In addition to the total score of $B E T Y-B Q$, the same time pain, functionality and fatigue, sexuality, emotional status and socialization subcategory of this questionnaire were evaluated on item basis among each patients.

Results: The demographics variables and BETY-BQ scores of the patients were shown in Table 1. There were a statistically significant differences among three groups. After post-hoc analysis, it was determined that there is no difference between the BETY-BQ scores of the outpatients and inpatients $(p>0.05)$, whereas the BETY-BQ scores of the patients who participated in the group exercise were lower $(p 0.05)$. When the items were analyzed, it was found that pain (items $2,3,5$, and 12), functionality and fatigue (items $6,7,11,26$, and 28), emotional status (items 16 and 17), and sleep (item 30) subcategory scores were also lower in patients who participated in BETY programme ( $\mathrm{p} 0.05)$.

Abstract Table 1. Demographic statistics and BETY-BQ scores

\begin{tabular}{|c|c|c|c|c|c|c|c|}
\hline & & \multicolumn{2}{|c|}{$\begin{array}{c}\text { Inpatient } \\
(\mathrm{n}=30)\end{array}$} & \multicolumn{2}{|c|}{$\begin{array}{l}\text { Outpatıent } \\
\qquad(n=44)\end{array}$} & \multicolumn{2}{|c|}{$\begin{array}{c}\text { Exercıse intervention } \\
\text { (BETY) } \\
(\mathrm{n}=\mathbf{3 1})\end{array}$} \\
\hline & & Female & Male & Female & Male & Female & Male \\
\hline \multirow[t]{2}{*}{ Gender (\%) } & & 61.3 & 37.8 & 87.2 & 12.8 & 53.7 & 7.4 \\
\hline & & \multicolumn{2}{|c|}{ XSD } & \multicolumn{2}{|c|}{ XSD } & \multicolumn{2}{|c|}{ XSD } \\
\hline Age (year) & & \multicolumn{2}{|c|}{46.3514 .56} & \multicolumn{2}{|c|}{46.0613 .26} & \multicolumn{2}{|c|}{48.6711 .89} \\
\hline BMI $\left(\mathrm{kg} / \mathrm{m}^{2)}\right.$ & & \multicolumn{2}{|c|}{24.195 .17} & \multicolumn{2}{|c|}{28.9818 .85} & \multicolumn{2}{|c|}{26.943 .84} \\
\hline \multirow[t]{2}{*}{ BETY-BQ (0-120) } & $p$ & \multicolumn{2}{|c|}{ XSD } & \multicolumn{2}{|c|}{ XSD } & \multicolumn{2}{|c|}{ XSD } \\
\hline & 0.027 & \multicolumn{2}{|c|}{49.1017 .94} & \multicolumn{2}{|c|}{45.6427 .93} & \multicolumn{2}{|c|}{33.8121 .73} \\
\hline
\end{tabular}

Conclusion: It is surprising that the biopsychosocial characteristics of the inpatients and outpatients were similar. According to this result, inpatients shouldnt be thought as worse than outpatients. On the other hand, the patients who participated in exercise intervention were improved in terms of biopsychosocial aspects. The positive effects of the BETY program on the biopsychosocial status of individuals have been demonstrated formerly [4]. It was concluded that inpatients should be supported to exercise in terms of their biopsychosocial needs during hospitalization period as well as rheumatic outpatients need.

\section{REFERENCES}

[1] Saketkoo, L.A. and J.D. Pauling, Qualitative methods to advance care, diagnosis, and therapy in rheumatic diseases. Rheumatic Disease Clinics of North America, 2018.

[2] Kisacik, P., et al., Investigating the effects of a multidimensional exercise program on symptoms and antiinflammatory status in female patients with ankylosing spondylitis. Complement Ther Clin Pract, 2016. 22: p. 38-43.

[3] NAL, E., et al., Romatizmalı hastalar iin bir yaşam kalitesi leğinin geliştirilmesi: madde havuzunun olussturulması. Journal of Exercise Therapy and Rehabilitation, 2017. 4(2): p. 67-75.

[4] Unal, E., et al. Effectiveness of a Biopsychosocial Exercise Approach in Rheumatic Diseases. in ARTHRITIS \& RHEUMATOLOGY. 2018. WILEY 111 RIVER ST, HOBOKEN 07030-5774, NJ USA.

Disclosure of Interests: None declared

DOI: 10.1136/annrheumdis-2019-eular.7221

\section{AB1374-HPR THE EFFECTIVENESS OF BIOPSYCHOSOCIAL EXERCISE PROGRAM ON PAIN COPING IN PATIENTS WITH ANKYLOSING SPONDYLITIS AND FIBROMYALGIA}

Aybüke Seven ${ }^{1}$, Aykut Özçadırcı' ${ }^{1}$, Gamze Arın ${ }^{1}$, Fatma Birgül Kumbaroğlư ${ }^{1}$, Nur Banu Karaca ${ }^{1}$, Ali Akdoğan ${ }^{2}$, Edibe Ünal ${ }^{1} .{ }^{1}$ Hacettepe University Faculty of Physical Therapy, Ankara, Turkey, ${ }^{2}$ Hacettepe University Faculty of Medicine, Department of Rheumatology, Ankara, Turkey

Background: Ankylosing spondylitis (AS) and fibromyalgia (FM) are rheumatic diseases with a high incidence in the community. Although many studies have been done on pain in these patient groups, the studies on coping with pain are very limited $(1,2)$. Bilişsel Egzersiz Terapi Yaklaşımı (BETY) is an exercise approach that developed in rheumatic patients. This approach has its own Biopsychosocial Questionnaire 
(BETY-BQ). This scale that assesses patients biopsychosocial status and includes the question about pain coping skill (3).

Objectives: The aim of this study is to the effectiveness of biopsychosocial exercise program on pain coping in with patients AS and FM.

Methods: Patients with AS and FM were included in the study and demographic data were recorded. Patients attended the BETY sessions for 8 weeks, 3 times a week for sixty minutes. BETY-BQ (3) was applied to individuals before and after 8 weeks. The answers to the question I don't know how to control my pain, which is the 5th question of the $\mathrm{BETY}-\mathrm{BQ}$ scale, was recorded as 5-point Likert, ranging between yesalways to no-never.

Results: 47 women with AS $(n=30)$ and FM $(n=17)$ included in the study. The mean age was 41.8311 .24 and 43.358 .86 and the body mass indexes were 26.385.15and 26.325 .15 for the AS and FM patients, respectively. There was a statistically significant difference in the ability of AS subjects to cope with pain before and after the BETY intervention ( $p$ $<0.05)$, there was no significant difference between individuals with FM before and after BETY intervention ( $p>0.05$ ) (Table 1).

Abstract AB1374HPR Table 1. Comparison of AS and FM patients before and after treatment

\begin{tabular}{|c|c|c|c|c|c|c|}
\hline & \multicolumn{2}{|c|}{ AS $(n=30)$} & \multicolumn{4}{|c|}{$\mathrm{FM}(\mathrm{n}=17)$} \\
\hline & $\begin{array}{c}\text { Pre- } \\
\text { treatment }\end{array}$ & $\begin{array}{c}\text { Post- } \\
\text { treatment }\end{array}$ & & $\begin{array}{c}\text { Pre- } \\
\text { treatment }\end{array}$ & $\begin{array}{c}\text { Post- } \\
\text { treatment }\end{array}$ & \\
\hline $\begin{array}{l}5 \text { th question } \\
(\%)\end{array}$ & & & $\begin{array}{c}\mathrm{p}= \\
0.36\end{array}$ & & & $\begin{array}{c}p= \\
0.314\end{array}$ \\
\hline Yes, always & 33.3 & 10 & & 23.5 & 17.6 & \\
\hline Yes, often & 20 & 13.3 & & 5.9 & 11.8 & \\
\hline $\begin{array}{l}\text { Yes, } \\
\text { sometimes }\end{array}$ & 16.7 & 30 & & 17.6 & 23.5 & \\
\hline Yes, rarely & 10 & 13.3 & & 41.2 & 11.8 & \\
\hline No, never & 20 & 33.3 & & 11.8 & 35.3 & \\
\hline
\end{tabular}

Conclusion: Although both AS and FM are rheumatic diseases, it is known that FM patients experience more intense psychosocial stress. They are, therefore, resistant to change (4). We found that the positive change in pain coping skill seen in the AS group is not seen in FM group. It is concluded that FM patients regarding in pain coping strategies they need to attend exercise programs and need to be educated about pain coping skills for a longer period.

\section{REFERENCES}

[1] Dean, L.E., et al., Global prevalence of ankylosing spondylitis. Rheumatology (Oxford), 2014. 53(4): p. 650-7.

[2] Cabo-Meseguer, A., G. Cerda-Olmedo, and J.L. Trillo-Mata, Fibromyalgia: Prevalence, epidemiologic profiles and economic costs. Med Clin (Barc), 2017. 149(10): p. 441-448.

[3] NAL, E., et al., Romatizmalı hastalar iin bir yaşam kalitesi leğinin geliştirilmesi: madde havuzunun oluşturulması. Journal of Exercise Therapy and Rehabilitation, 2017. 4(2): p. 67-75.

[4] Clauw, D.J., Fibromyalgia and related conditions. Mayo Clin Proc, 2015. 90(5): p. 680-92.

Disclosure of Interests: None declared

DOI: 10.1136/annrheumdis-2019-eular.7229

\section{AB1375-HPR EFFECT OF SCHROTH METHOD AND SCIENTIFIC EXERCISE APPROACH TO SCOLIOSIS (SEAS) ON THE COBB ANGLE AMONG THE ADOLESCENT WITH IDIOPATHIC SCOLIOSIS A COMPARATIVE STUDY}

Jalpa Shah, T Padma Priya., Pahinian Arumugam, R Kousalya. Sri Venkateshwaraa Medical College Hospital and Research Centre, physiotherapy, Puducherry, India

Background: Scoliosis is a three-dimensional deformity of the spine and trunk leading to physical and functional disability. Among adolescent, idiopathic scoliosis is the most common $(80 \%-89 \%)$ form of scoliosis with prevalence ranging between $0.47 \%$ and $5.2 \%$ in general population ${ }^{1}$. As the evidence on the comparative efficacy of various physical therapy in scoliosis is sparse, we conducted a comparative study assessing efficacy of Schroth method of exercise group $(\mathrm{SEG})^{2}$ and scientific exercise approach to scoliosis group (SEASG) ${ }^{3}$ in adolescents with idiopathic scoliosis.

Objectives: To compare efficacy of schroth method and SEAS among adolescent with scoliosis.
Methods: Thirty subjects, both male and female of the age group of 10 to 18 years, with mild-moderate idiopathic scoliosis defined as the spinal radiographic Cobb angle in the range of 20 to 45 and riser sign of 0-2 were randomly allocated to Schroth method of exercise group (SEG $\mathrm{n}=15$ ) and scientific exercise approach to scoliosis group (SEASG, $\mathrm{n}=15$ ) Subjects with diagnosis of spinal injury, previous spinal surgery, gibbus, limb deformity, infection and malignancy were excluded. The SEG and SEASG performed Schroth and scientific exercise respectively, 5 times a week for 7 weeks. To quantify the magnitude of spinal deformity, Cobb angle measurements were obtained by using radiograph to gain pre-post interventional differences. (Figure 1 )

Results: SEG showed the significant changes in pre (mean sd 31.2 5.20) and post (mean sd 27.4 5.17) Cobb angle measurements. SEASG also showed the significant changes in pre (mean sd 31.33 5.26) and post (mean sd 29.4 5.9) Cobb angle measurements (Figure 2). Comparing both the groups by unpaired t test suggested SEG to be more efficacious than the SEASG with the $t$ value (4.22) for change in Cobb angle $(p<.0 .0001)$ (Figure 3 )

Conclusion: The study establishes the role of physical therapy in idiopathic scoliosis of mild to moderate degree among adolescents with Schroth method of exercise performs better compared to the SEAS in patients with mild to moderate scoliosis.

\section{REFERENCES}

[1] Negrini, Stefano \& Fusco, Claudia \& Minozzi, S \& Atanasio, Salvatore \& Zaina, Fabio \& Romano, Michele. (2008). Exercises reduce the progression rate of adolescent idiopathic scoliosis: Results of a comprehensive systematic review of the literature. Disability and rehabilitation. 30. 772-85.

[2] Schreiber S, Parent EC, Moez EK, Hedden DM, Hill D, Moreau MJ, Lou E, Watkins EM, Southon SC. The effect of Schroth exercises added to the standard of care on the quality of life and muscle endurance in adolescents with idiopathic scoliosis-an assessor and statistician blinded randomized controlled trial:"SOSORT 2015 Award Winner". Scoliosis. 2015 Sep 18:10:24. doi:10.1186/s13013-015-0048-5

[3] Romano M, Negrini A, Parzini S, et al. SEAS (Scientific Exercises Approach to Scoliosis): a modern and effective evidence based approach to physiotherapic specific scoliosis exercises. Scoliosis. 2015;10:3. Published 2015 Feb 5.

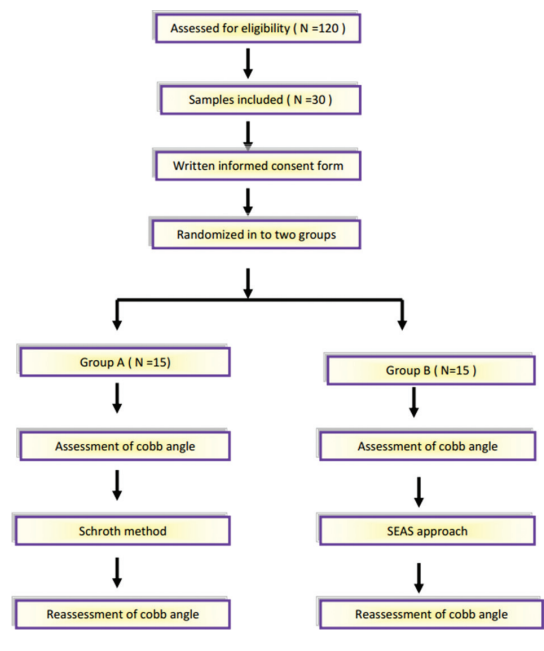

GRAPHICAL PRESENTATION OF WITHIN GROUP ANALYSIS

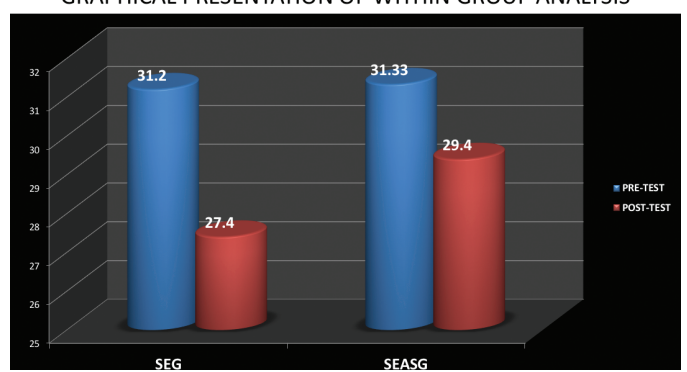

